\title{
General Psychiatry Marijuana use and repeated attempted suicide among senior high school students in Ghana: Evidence from the WHO Global School-Based Student Health Survey, 2012
}

John Tetteh (1) , ${ }^{1}$ George Ekem-Ferguson (i) , ${ }^{2}$ Swithin Mustapha Swaray (D) , ${ }^{3}$ Nuworza Kugbey, ${ }^{4}$ Emmanuel Nii-Boye Quarshie (D) , ${ }^{5}$ Alfred Edwin Yawson ${ }^{1}$
To cite: Tetteh J, EkemFerguson G, Swaray SM, et al. Marijuana use and repeated attempted suicide among senior high school students in Ghana: Evidence from the WHO Global School-Based Student Health Survey, 2012. General Psychiatry 2020;33:e100311. doi:10.1136/ gpsych-2020-100311

Received 18 June 2020 Revised 23 July 2020 Accepted 14 August 2020
Check for updates

(C) Author(s) (or their employer(s)) 2020. Re-use permitted under CC BY-NC. No commercial re-use. See rights and permissions. Published by BMJ.

For numbered affiliations see end of article.

Correspondence to

John Tetteh;

bigjayasamoah@gmail.com

\section{ABSTRACT}

Background The association between substance use including marijuana use and attempted suicide has been well documented. However, little is known about marijuana use and its association with attempted suicide repetition among young people in low-income and middle-income contexts.

Aims This analysis was conducted to assess the factors associated with marijuana use and ascertain marijuana use as a determinant of repeated attempted suicide among senior high school (SHS) students in Ghana. Methods Data from the 2012 Global School-Based Student Health Survey in Ghana was used for this study. Modified Poisson, Logistic and Probit models weighted with Mahalanobis distance matching within propensity calliper were employed separately to determine the hypothetical association between marijuana use and repeated attempted suicide. All analysis was performed using Stata 16 and $p \leq 0.05$ was deemed statistically significant.

Results The prevalence estimates of marijuana use and repeated attempted suicide among SHS students in Ghana were $3.4 \%$ (95\% Cl: 2.3 to 5.1$)$ and $11.5 \%$ (95\% Cl: 9.1 to 14.4), respectively. The prevalence of marijuana use was significantly associated with school grade, smoking exposure, parent smoker, alcohol intake and truancy. Marijuana use was positively associated with repeated attempted suicide among SHS in Ghana ( $\phi$ correlation $=0.23, p<0.001)$. Repeated attempted suicide among students who use marijuana was approximately threefold and fivefold significant compared with nonmarijuana use students, based on the Poisson (adjusted prevalence ratio: $3.02 ; 95 \% \mathrm{Cl}: 1.67$ to $5.43, \mathrm{p}<0.001$ ) and Logistic (adjusted OR:5.06; 95\% Cl: 3.19 to 11.64 , $\mathrm{p}<0.001)$ estimates respectively. Also, the Probit model showed that marijuana use significantly increased the log count of repeated attempted suicide by $95 \%$ (aß: 0.95 ; $95 \%$ Cl: 0.49 to $1.41, p<0.001$ ).

Conclusion Marijuana use does not only influence the onset of suicidal attempts but also repeated attempted suicide among SHS students in Ghana. Special attention is required for suicide attempters with a history of repeated attempts and current marijuana use among SHS students in Ghana. Early identification of the potential risk and protective factors is recommended to inform school-based interventions. National level structured school-based substance abuse interventions and health promotion programmes would be useful.

\section{INTRODUCTION}

Substance use among young people constitutes a major public health issue. Besides alcohol and tobacco, marijuana is one of the most common substances used globally among the general population, with particularly high rates of use among adolescents and young adults in sub-Saharan African countries, including Ghana. ${ }^{1}$ Globally, 13.8 million young people (mostly students) aged 15-16 years (prevalence of $5.6 \%$ ) used marijuana at least once in the previous 12 months. ${ }^{2}$ In Ghana, the prevalence of the use of marijuana among young people aged 11-19 years is $5.3 \%{ }^{3}$ and has become an issue of public health concern.

There has been a lot of debate in Ghana concerning the legalisation of marijuana. The law is tough even for relatively minor offences like possession and use of the drug. Ghana's parliament in March 2020 passed into law the Narcotics Control Commission Bill 2019, legalising the growing of marijuana for health and industrial purposes. ${ }^{4}$ It, however, does not give a blanket license for the growing of marijuana in the country and it is still illegal to cultivate or possess marijuana without lawful authorisation. Any substance in the cannabis family with tetrahydrocannabinol content above the level of $0.3 \%$ is a highgrade substance which is prohibited by law in Ghana. The key purpose of the new law is to treat drug use and dependence as a public health issue. ${ }^{5}$ 
The common route of administration of marijuana is through inhalation. The greenish-grey shredded leaves and flowers of the Cannabis sativa plant are smoked (along with stems and seeds) in cigarettes, cigars, pipes, water pipes or 'blunts' (marijuana rolled in the tobaccoleaf wrapper from a cigar). Hashish is a related product created from the resin of marijuana flowers and is usually smoked (by itself or in a mixture with tobacco) but can be ingested orally. Marijuana can also be used to brew tea, and its oil-based extract can be mixed into food products. ${ }^{5}$ Among senior high school (SHS) students in Ghana, it is normally smoked or mixed with 'shito' (pepper sauce).

Several factors related to marijuana use among schoolgoing adolescents in Ghana have been reported. ${ }^{67}$ Key among them include truancy, current cigarette smoking, number of close friends, bullying victimisation, having been attacked and parental substance use. ${ }^{6}$ Whereas similar factors have been reported elsewhere, wealth index, community characteristics and difficult temperaments have also been reported as associated with marijuana use among young people. ${ }^{89}$

Regular use of marijuana during adolescence is of particular concern due to the associated likelihood of adverse health consequences, including the impairment of memory, judgement and personality, ${ }^{10}$ it has also been implicated for increased risk of moderate to severe negative mental health outcomes including bipolar, mood disorders, anxiety, cognitive, depressive disorders, suicide attempt and eventual suicide. ${ }^{11}$

Suicide is a major global public health concern, with nearly 800000 people taking their lives annually, and many more attempting. ${ }^{12}$ In sub-Saharan Africa, attempted suicide is among the top 12 causes of death among young people. ${ }^{12}$ Repetition of attempted suicide (or repeated suicide attempt) represents the single most important risk factor for suicide in the general population. Thus, recent significant research efforts from low-income and middle-income countries (LMICs) have focused on examining the factors associated with attempted suicide among young people. ${ }^{13}$ A recent study conducted by Carvalho and colleagues suggested a strong association between cannabis use and suicide attempts in adolescents living in LMICs. ${ }^{14}$ However, as can be said of Ghana, whereas emerging evidence has underscored the key factors associated with marijuana use ${ }^{6}$ and those related to the onset of attempted suicide among in-school adolescents, ${ }^{3} 15$ there is a paucity of published studies providing evidence on the association between marijuana use and the repetition of attempted suicide among in-school adolescents. ${ }^{14}$ Therefore, in the current analysis, we sought to (i) estimate the prevalence of marijuana use and describe its associated factors and (ii) examine marijuana use as a determinant for repeated attempted suicide among SHS students in Ghana.

\section{METHODS}

\section{Data source}

The current dataset for Ghana on Global School-Based Student Health Survey (GSHS) 2012 conducted by WHO, in collaboration with the Center for Disease Control and Prevention (CDC), the United Nations Children's Fund, United Nations Educational, Scientific and Cultural Organisation and the United Nations Programme on HIV/AIDS was used for this study. The GSHS uses a selfadministered questionnaire to obtain data on students' health behaviour and protective factors. The core mandate of GSHS is to provide data on the prevalence of health behaviours and protective factors among students to evaluate school health and youth health promotion programmes. ${ }^{16}$ This study used the Ghana Senior High GSHS (Grades SHS 1-4) model which measured alcohol use, dietary behaviours, drug use, hygiene, mental health, physical activity, protective factors, sexual behaviours, tobacco use and violence and unintentional injury validated in the Ghanaian context. ${ }^{16}$ The Ghana SHS GSHS was moderated by the Middle Tennessee State University in collaboration with the Ghana Education Service (GES).

\section{Design and sampling}

The Ghana SHS GSHS study adopted a cross-sectional study design with a two-stage cluster sampling method. At the first stage, schools were selected with probability proportional to enrolment size in Ghana within 12 enumeration areas from 24 primary sampling units (PSUs) across the 10 administrative regions at the time. In the second stage, classes were randomly selected which gave all students an equal probability of participating in the study. ${ }^{16}$ GSHS used a scannable answer sheet for students to self-report their responses to each question.

\section{Study participants}

The 2012 Ghana SHS GSHS involved students in SHS 1-4, which are typically attended by students aged $13-17$ years; however, the study involved all the students from SHS 1-4, regardless of the age interval. The study involved 1984 students with a response rate of $74 \%$, while the school response rate was $96 \%$ and the overall response rate was $71 \%$. Based on Strengthening the Reporting of Observational Studies in Epidemiology (STROBE) recommendation for cross-sectional study design, implementation and reporting, missing responses were strictly excluded in our analysis. ${ }^{17}$ A detailed number of missing responses for all covariates can be found in online supplemental table 1. Flowchart defining the sampling methods and final participants can be found in figure 1 .

\section{Outcome measure}

Two outcome variables were involved in this study, namely marijuana use within the past 30 days and multiple suicidal attempts. Marijuana in the Ghanaian society is also known as wee, Jah, Indian hemp, ahabammono, ganja, osime, ntampe, waakye, kush and amnesia. The GSHS asked students During the past 30 days, how many times have you 


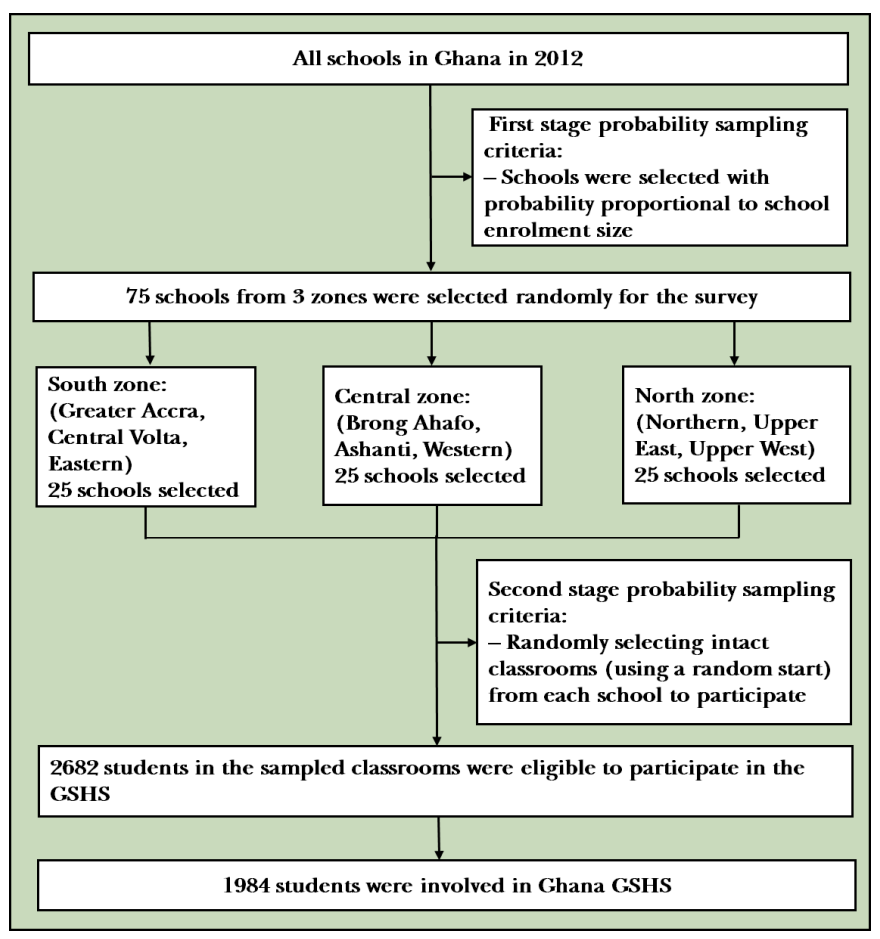

Figure 1 Flowchart defining participated students in Ghana GSHS, 2012. GSHS, Global School-Based Student Health Survey.

used marijuana? with responses: 0 time, 1 or 2 times, $3-9$ times, 10 - 19 times and 20+ times. An artificial dummy binary variable was generated for this outcome variable as: No ( 0 time $)=0$ or Yes ( 1 or 2 times, $3-9$ times, $10-19$ times and $20+$ times $)=1$ to determine the prevalence of marijuana use among SHS students in Ghana. Repetition of suicidal attempts was assessed with the GSHS question, During the past 12 months, how many times did you actually attempt suicide? Responses were categorised as 0 time, 1 time, $2-3$ times, $4-5$ times and 6+ times. Again, we generated an artificial repeated suicide attempt dummy binary variable by combining 0 and 1 time responses as 'No=0' and $2-6+$ times responses as 'Yes $=1$ ' to enable the estimation of the prevalence of repeated attempted suicide among SHS students in Ghana. Two additional suicidal behaviour domains were also considered in this study: suicidal ideation (During the past 12 months, did you ever seriously consider attempting suicide?) and suicidal plan (During the past 12 months, did you make a plan about how you would attempt suicide?), all of which were recoded as 'Yes $=1$ ' or ' $\mathrm{No}=0$ '.

\section{Covariates}

This study assessed 15 covariates involving sex differential, age group ( $\leq 17$ or $18+$ ), school grade (SHS 1 , SHS 2, SHS 3 or SHS 4), the experience of hunger (no or yes), bullying victimisation (no or yes), experience of insomnia (no or yes), having close friends (none, 1 friend, 2 friends or 3+ friends), weekly smoking exposure (never, $1-2$ or $3+$ ), parent smoker (no or yes), alcohol intake (no or yes), truancy (no or yes), social support at school (no or yes), loneliness (no or yes), checking of homework by a parent (no or yes) and engaging in a physical fight (no or yes). Detailed variable definition, type of variable, measurement and scale of measurement used in this study can be found in online supplemental table 1 .

\section{Data analysis}

Statistical weighting estimates were strictly considered in this study by adjusting for the study design adopted by Ghana SHS GSHS to reflect the probability of sampling students to reduce bias in our estimation. The weighting was done by adjusting the PSU, stratification and the sampling weights as estimated by GSHS. Furthermore, individual weights were normalised by dividing individual weights by 1000000 . This process was deemed appropriate since the data used was weighted at the data management stage.

The hypothetical idea was to assess if marijuana use was associated with the repetition of suicidal attempts. In this case, the Rao-Scott $\chi^{2}$ test of independence for a complex survey was employed at the first stage of analysis to assess covariates independence between outcome variable (marijuana use; yes or no). Poisson regression analysis was also employed to assess significant factors associated with marijuana use among the participants (unadjusted and adjusted estimates).

Due to the artificial dummy nature of our study outcome variables, phi correlation (fourfold correlational analysis) was performed to assess the strength of the relationship between marijuana use and suicidal domains (suicidal ideation, suicidal plan and repeated attempted suicide).

A matching procedure was also adopted in selecting control in a sample that has the same covariate values to those in the treated sample to study the effects of certain exposures. ${ }^{18}$ Mahalanobis distance within the propensity score calliper matching procedure was adopted to obtain a credible counterfactual estimate on our study outcome as proposed by Rubin and Thomas. ${ }^{18}$ Common support and strong ignorability assumption in propensity score matching were also carried out to confirm the assumption of our chosen methodological approach. The assumption of common support ensures that there is sufficient overlap in the covariates of treated (marijuana use) and untreated (no marijuana use) components to find adequate matches. ${ }^{19}$ After preprocessing the data with Mahalanobis distance matching within propensity score calliper, quantification of the association between marijuana use and repeated attempted suicide was performed by adopting three statistical models separately involving Modified Poisson, Modified Logistic and Modified Probit regression respectively with robust SE estimations. These models were adopted to estimate the probability of repeated attempted suicide by looking at the log-likelihood ratio, log odds and coefficient individually. The analysis was performed using Stata 16 and a $\mathrm{p} \leq 0.05$ deemed statistically significant. 
Table 1 Demographic characteristics prevalence of marijuana use among senior high school students in Ghana, WHO GSHS, $2012^{15}$

\begin{tabular}{|c|c|c|c|c|}
\hline \multirow[t]{2}{*}{ Covariates } & \multicolumn{2}{|c|}{ Marijuana use status } & \multirow[t]{2}{*}{ Total } & \multirow[t]{2}{*}{ Rao-Scott $\chi^{2}$} \\
\hline & No & Yes & & \\
\hline \multirow[t]{2}{*}{ Prevalence $(95 \% \mathrm{Cl})$} & $\begin{array}{l}96.4 \% \text { (94.9 to } \\
97.7)\end{array}$ & $3.4 \%$ (2.3 to 5.1 ) & & \\
\hline & Weighted \% & Weighted \% & $\mathrm{n}$ & \\
\hline Sex & & & & 1.78 \\
\hline Male & 96.0 & 4.0 & 1038 & \\
\hline Female & 97.4 & 2.6 & 882 & \\
\hline Age group & & & & 0.26 \\
\hline$\leq 17$ & 96.2 & 3.8 & 886 & \\
\hline $18+$ & 96.8 & 3.2 & 1038 & \\
\hline Grade & & & & 1.41 \\
\hline SHS 1 & 96.8 & 3.2 & 560 & \\
\hline SHS 2 & 94.6 & 5.4 & 372 & \\
\hline SHS 3 & 97.5 & 2.5 & 606 & \\
\hline SHS 4 & 97.5 & 2.5 & 378 & \\
\hline Experience of hunger & & & & 2.21 \\
\hline No & 98.1 & 1.9 & 668 & \\
\hline Yes & 95.8 & 4.2 & 1260 & \\
\hline Bullying victimisation & & & & $13.35^{\star \star \star}$ \\
\hline No & 97.9 & 2.1 & 1110 & \\
\hline Yes & 94.6 & 5.4 & 700 & \\
\hline Experience insomnia & & & & $9.45^{\star \star}$ \\
\hline No & 98.3 & 1.7 & 514 & \\
\hline Yes & 96.1 & 3.9 & 1413 & \\
\hline Close friends & & & & 1.52 \\
\hline None & 95.6 & 4.4 & 274 & \\
\hline 1 friend & 97.7 & 2.3 & 572 & \\
\hline 2 friends & 95.9 & 4.1 & 481 & \\
\hline $3+$ friends & 97.2 & 2.8 & 589 & \\
\hline Weekly smoking exposure & & & & $47.84^{\star \star \star}$ \\
\hline Never & 98.4 & 1.6 & 1310 & \\
\hline $1-2$ & 96.8 & 3.2 & 309 & \\
\hline $3+$ & 89.3 & 10.7 & 311 & \\
\hline Parent smoker & & & & $61.39^{\star \star \star}$ \\
\hline No & 97.4 & 2.6 & 1768 & \\
\hline Yes & 87.5 & 12.5 & 158 & \\
\hline Alcohol intake & & & & $53.71^{\star \star \star}$ \\
\hline No & 98.1 & 1.9 & 1595 & \\
\hline Yes & 86.9 & 13.1 & 222 & \\
\hline Truancy & & & & $47.99^{\star \star \star}$ \\
\hline No & 98.3 & 1.7 & 1313 & \\
\hline Yes & 93.4 & 6.6 & 596 & \\
\hline Social support at school & & & & \\
\hline No & 96.9 & 3.1 & & \\
\hline
\end{tabular}

Continued 
Table 1 Continued

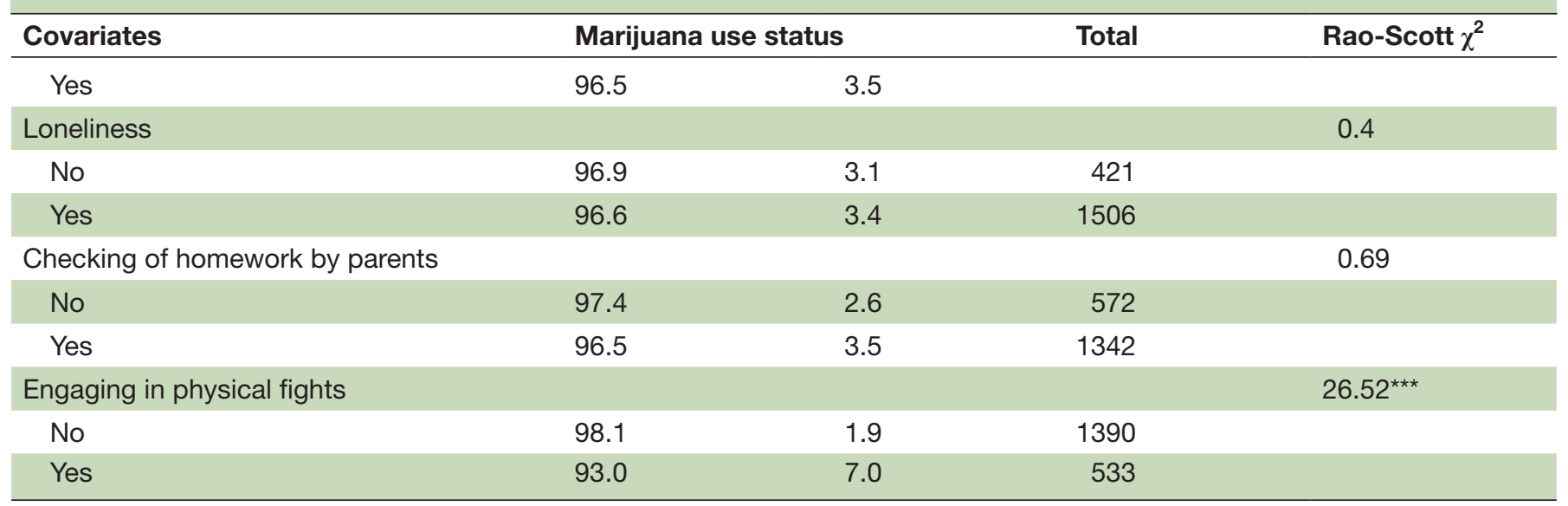

Rao-Scott is a design-based $\chi^{2}$ test; $p$ value indication: ${ }^{* *} \mathrm{p}<0.01,{ }^{* \star *} \mathrm{p}<0.001$.

GSHS, Global School-Based Student Health Survey; SHS, senior high school.

\section{Ethics}

The GES ethical procedures were strictly observed regarding student participation in research activities. Informed consent was obtained from all heads of participated schools, teachers and all students. For underage students, assent and parental consent were obtained for each. The guidelines for collecting, labelling and packing of filed collected data by WHO/CDC were strictly observed.

\section{Data acquisition}

Public domain dataset downloaded on 25 March 2020 from https://extranet.who.int/ncdsmicrodata/index. php/catalog/422/get_microdata was used. The Ghana GSHS, 2012 reference number was GHA_2012_GSHS_ v01_M and the study was conducted by the WHO and the Center for Disease Control and Prevention.

\section{RESULTS}

The prevalence of marijuana use was 3.4\% (95\% CI: 2.3 to 5.1) and Rao-Scott test of independence showed a statistically significant association between the prevalence of marijuana use and bullying victimisation, insomnia, weekly smoking exposure, parent smoker, alcohol intake, truancy and engaging in a physical fight $(\mathrm{p}<0.05$; see table 1).

Poisson test of association estimate showed that grade, weekly smoking exposure, parent smoker, alcohol intake and truancy were significantly associated with marijuana use among SHS students. The analysis estimated that SHS 2 students were approximately three times likely to use marijuana compared with SHS 4 students (adjusted prevalence ratio (aPR): 2.77 ; 95\% CI: 1.26 to $6.07, \mathrm{p}=0.015$ ). Also, students who were three times or more exposed to weekly smoking and had a parent smoker were approximately two times more likely to use marijuana, compared with those who reported no exposure to smoking and had no parent smoker, respectively (aPR: 2.32; 95\% CI: 1.11 to 4.85, $\mathrm{p}=0.039$ and aPR: 2.07 ; $95 \%$ CI: 2.15 to $3.43, \mathrm{p}=0.009$, respectively). Alcohol use and truancy among students significantly influenced marijuana use by approximately three times, respectively (aPR: $3.12 ; 95 \%$ CI: 1.30 to 7.47 , $\mathrm{p}=0.015$ and aPR: 3.48 ; $95 \%$ CI: 1.76 to $6.89, \mathrm{p}=0.002$, respectively) (see table 2 ).

\section{Suicidal ideation, suicidal plan and repetition of suicidal attempts correlation with marijuana use}

The prevalence estimates of suicidal ideation, suicidal planning and repeated attempted suicide among SHS students in Ghana was $18.9 \%$ (95\% CI: 16.8 to 21.2), $23.1 \%$ (95\% CI: 19.2 to 27.5 ) and $11.5 \%$ (95\% CI: 9.1 to 14.4), respectively (see table 3 ). Marijuana use was positively correlated with suicidal ideation, suicidal planning and repeated attempted suicide among SHS in Ghana $(\mathrm{p} \leq 0.001)$ (see table 3$)$.

Testing for common assumption in the study showed an overlap of the propensity scores matching for students who use marijuana and students who do not use marijuana. The result showed a clear overlap in which the common support assumption was fulfilled (figure 2).

The balancing methods clearly showed that adopting Mahalanobis distance matching within propensity calliper (1:1) reduced bias among significant covariates associated with marijuana use extremely to $0 \%$ after matching. This makes the Mahalanobis distance matching within propensity calliper (1:1) appropriate for this study (figure 3).

Quantifying the association between marijuana use and repeated attempted suicide was performed by controlling for significant factors associated with marijuana use (Mahalanobis weights) and adjusting for other demographic covariates by using Poisson, Logistic and Probit regression. The analysis showed that marijuana use is significantly associated with repeated suicide attempts among SHS students in Ghana. The prevalence of repeated attempted suicide among students who use marijuana was approximately threefold higher compared with non-marijuana use students, from Poisson estimate (aPR: 3.02; $95 \%$ CI: 1.67 to 5.43, p<0.001). Similarly, the Logistic 
Table 2 Poisson estimation assessing factors significantly associated with marijuana use among senior high school students in Ghana, WHO GSHS, $2012^{15}$

\begin{tabular}{|c|c|c|}
\hline Covariate & $\mathrm{PR}(95 \% \mathrm{Cl})$ & aPR $(95 \% \mathrm{Cl})$ \\
\hline \multicolumn{3}{|l|}{ Sex } \\
\hline Female & Ref & \\
\hline Male & 1.55 (0.75 to 3.18$)$ & \\
\hline \multicolumn{3}{|l|}{ Age group } \\
\hline$\leq 17$ & Ref & \\
\hline $18+$ & 0.85 (0.41 to 1.73$)$ & \\
\hline \multicolumn{3}{|l|}{ Grade } \\
\hline SHS 4 & Ref & Ref \\
\hline SHS 1 & 1.28 (0.35 to 4.65$)$ & 2.11 (0.74 to 6.01$)$ \\
\hline SHS 2 & $2.12(1.28 \text { to } 3.49)^{* \star}$ & $2.77(1.26 \text { to } 6.07)^{\star}$ \\
\hline SHS 3 & 0.98 (0.43 to 2.21$)$ & 1.14 (0.44 to 2.91$)$ \\
\hline \multicolumn{3}{|c|}{ Experience of hunger } \\
\hline No & Ref & \\
\hline Yes & 2.14 (0.68 to 6.72$)$ & \\
\hline \multicolumn{3}{|c|}{ Bullying victimisation } \\
\hline No & Ref & Ref \\
\hline Yes & $2.55(1.42 \text { to } 4.57)^{\star \star}$ & 1.54 (0.77 to 3.07$)$ \\
\hline \multicolumn{3}{|c|}{ Experience insomnia } \\
\hline No & Ref & Ref \\
\hline Yes & $2.28(1.25 \text { to } 4.15)^{* *}$ & 0.90 (0.42 to 1.92$)$ \\
\hline \multicolumn{3}{|l|}{ Close friends } \\
\hline $3+$ friends & Ref & \\
\hline None & 1.58 (0.79 to 3.15$)$ & \\
\hline 1 friend & 0.84 (0.35 to 2.00$)$ & \\
\hline 2 friends & 1.45 (0.73 to 2.87$)$ & \\
\hline \multicolumn{3}{|c|}{ Weekly smoking exposure } \\
\hline Never & Ref & Ref \\
\hline $1-2$ & $2.01(1.01 \text { to } 4.02)^{\star}$ & 1.25 (0.49 to 3.15$)$ \\
\hline $3+$ & $6.67(4.01 \text { to } 10.11)^{\star \star \star}$ & $2.32(1.11 \text { to } 4.85)^{\star}$ \\
\hline \multicolumn{3}{|c|}{ Parent smoker } \\
\hline No & Ref & Ref \\
\hline Yes & $4.87(3.01 \text { to } 7.86)^{\star \star \star}$ & $2.07(2.15 \text { to } 3.43)^{\star \star}$ \\
\hline \multicolumn{3}{|c|}{ Alcohol intake } \\
\hline No & Ref & Ref \\
\hline Yes & $6.99(3.59 \text { to } 13.64)^{\star \star \star}$ & $3.12(1.30 \text { to } 7.47)^{\star}$ \\
\hline \multicolumn{3}{|l|}{ Truancy } \\
\hline No & Ref & Ref \\
\hline Yes & $4.00(2.52 \text { to } 6.33)^{\star \star \star}$ & $3.48(1.76 \text { to } 6.89)^{\star \star \star}$ \\
\hline \multicolumn{3}{|c|}{ Social support at school } \\
\hline No & Ref & \\
\hline Yes & 1.23 (0.53 to 2.39$)$ & \\
\hline \multicolumn{3}{|l|}{ Loneliness } \\
\hline No & Ref & \\
\hline Yes & 1.12 (0.76 to 1.66$)$ & \\
\hline
\end{tabular}


Table 2 Continued

\begin{tabular}{lll}
\hline Covariate & PR $(95 \% \mathrm{Cl})$ & aPR $(95 \% \mathrm{Cl})$ \\
\hline Homework checking by parents & & \\
No & Ref & \\
Yes & $1.35(0.61$ to 2.98$)$ & \\
Engaging in physical fights & Ref & Ref \\
No & $3.67(2.05 \text { to } 6.59)^{\star \star *}$ & 1.85 (0.75 to 4.55$)$ \\
\hline Yes &
\end{tabular}

aPR is adjusted prevalence ratio from Poisson regression; $p$ value indication: ${ }^{\star} \mathrm{p}<0.05,{ }^{\star \star} \mathrm{p}<0.01,{ }^{\star * \star} \mathrm{p}<0.001$; Ref denotes Reference category used for inferences.

GSHS, Global School-Based Student Health Survey; SHS, senior high school.

regression predicted approximately fivefold increased odds of repeated attempted suicide (adjusted OR (aOR): 5.06; 95\% CI: 3.19 to $11.64, \mathrm{p}<0.001)$; the Probit model also showed that marijuana use significantly increased the log odds of multiple suicidal attempts by $95 \%$ (a $\beta$ : 0.95 ; 95\% CI: 0.49 to $1.41, \mathrm{p}<0.001$ ) (see table 4 ).

Another adjusted covariate that was significantly associated with repeated attempted suicide was bullying victimisation. Our analysis showed that SHS students who were victims of bullying were approximately three times more likely to repeat attempted suicide, compared with students who did not report bullying victimisation (Poisson estimate; aPR: 3.10; 95\% CI: 1.63 to 5.89, $\mathrm{p}=0.001$ and Logistic estimate; aOR: $3.70 ; 95 \%$ CI: 1.74 to $7.88, \mathrm{p}=0.001$ ). Probit model showed that bullying victimisation among SHS students significantly increased the chances of repeated attempted suicide by $69 \%$ (aß: 0.69 ; $95 \%$ CI: 0.29 to $1.09, \mathrm{p}=0.001$ ) (see table 4 ).

\section{DISCUSSION}

\section{Main findings}

This analysis estimated the prevalence of marijuana use and assessed its association with repeated attempted suicide among SHS students in Ghana. The prevalence rate of marijuana use in this study $(3.4 \%)$ was relatively lower than the reported rate of $9 \%$ found among junior high school students ${ }^{20}$ and $5.3 \%$ among school-going

Table 3 Prevalence estimates of suicidal ideation, planning and repetition and phi correlation with marijuana use among senior high school students in Ghana, WHO GSHS, $2012^{15}$

\begin{tabular}{lll}
\hline Suicidal domain & Prevalence $(95 \% \mathrm{Cl})$ & $\begin{array}{l}\boldsymbol{\varphi} \text { with } \\
\text { marijuana use }\end{array}$ \\
\hline Suicidal ideation & $18.9(16.8$ to 21.2$)$ & $0.11^{\star \star *}$ \\
Suicidal planning & $23.1(19.2$ to 27.5$)$ & $0.10^{\star \star *}$ \\
$\begin{array}{l}\text { Repeated } \\
\text { attempted suicide }\end{array}$ & $11.5(9.1$ to 14.4$)$ & $0.23^{\star \star *}$ \\
\hline
\end{tabular}

$\phi$ phi correlation used to measure the strength of a relationship between two dummy artificial variables; $p$ value indication: ${ }^{* * *} \mathrm{p}<0.001$.

GSHS, Global School-Based Student Health Survey. adolescents in Ghana. ${ }^{21}$ In Africa, our estimated prevalence rate is comparatively fivefold lower to the proportion of adolescents who use cannabis in sub-Saharan Africa $(15.6 \%){ }^{22}$ The differences could be as a result of different participants and methodological approaches adopted in the various studies. The prevailing socioeconomic variations in these countries could also explain the disparity in the rates of marijuana use. For example, whereas some countries have very stringent regulations on marijuana possession and use, access to marijuana and possession in other countries are relaxed.

This analysis found a significant association between the prevalence of marijuana use and school grade or level, smoking exposure within 7 days, parent smoker, alcohol intake and truancy after adjusting for significant factors influencing marijuana use from univariate Poisson regression. The lower grade (junior) of SHS students was found to have a higher chance of using marijuana as compared with senior students. This finding is consistent with previous literature which suggested that junior students' marijuana use was 10-fold over their senior counterparts. ${ }^{23}$ This could be explained by exposure to marijuana use by senior students, whereas resistance may lead to bullying of junior students by their seniors. This is supported by the findings from this study where SHS students who have had multiple exposures to smoking during the past week were twice as likely to use marijuana. These findings support previous studies that found

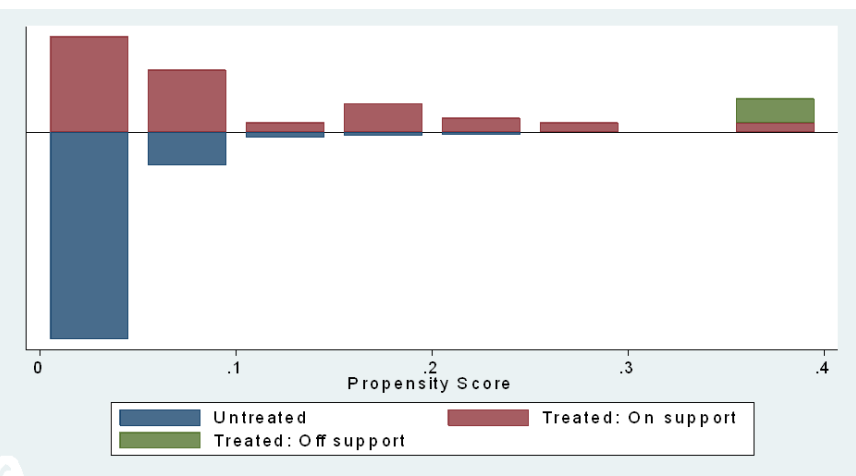

Figure 2 Propensity score matching assessing the assumption of common support. 


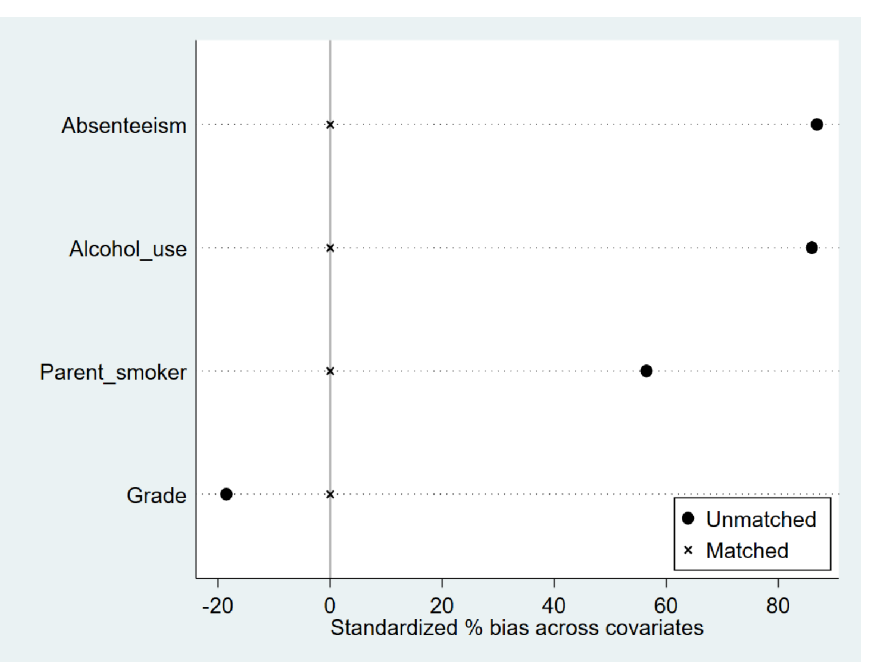

Figure 3 Standardize percentage bias across significant covariates associated with marijuana use showing Mahalanobis distance matching within propensity caliper $(1: 1)$.

similar associations, where bullying victimisation was associated with marijuana use among students. ${ }^{62}$

Unsurprisingly, alcohol use and parental smoking were found to be significantly and positively associated with marijuana use among SHS students. These findings can be viewed within the lens of social learning as posited by the WHO that social and contextual factors such as alcohol use and family factors including parental smoking behaviour significantly increase the risk of drug use among adolescents. ${ }^{8}$ Recent evidence from Ghana suggests parental substance use as a strong predictor of marijuana use among students. ${ }^{6}$

\section{Marijuana use and repeated attempted suicide among SHS students in Ghana}

Evidence from LMICs suggests a strong positive association between marijuana use and attempted suicide among young people. ${ }^{1314}$ Our study has extended this evidence by indicating that marijuana use has a strong positive association with repeated attempted suicide among SHS students in Ghana. After controlling for confounding factors associated with marijuana use and adjusting for demographic covariates, this study found marijuana use to be significantly associated with repeated attempted suicide among SHS students in Ghana. The students who reported marijuana use were over threefold more likely to repeat suicide attempts. Relative to our findings, studies have found that marijuana use increased the occurrence of both suicide ideations and planning, while those who use marijuana had an increased risk for the onset and repetition of suicide attempts. ${ }^{6} 24$

A pervasive wrong perception among students and young people in Ghana is that marijuana use has a calming effect on the mind and helps improve concentration levels. However, scientific evidence suggests that marijuana alters brain development, impairs cognitive functions and leads to poor academic performance. ${ }^{9}$
Chronic effects of marijuana use among young people could be related to suicide ideation and attempts by influencing the onset of other mental disorders, schoolwork problems and sociofamilial problems including low grades, academic failure and family discord. Thus, the comorbidities of marijuana use and mental disorders could increase the chances of the repetition of attempted suicide among young people. According to the WHO, early and frequent marijuana use can be deleterious in young people, by possibly affecting brain development (memory and cognition) and subsequent use of other drugs and eventual juvenile offending. ${ }^{8}$

Our analysis has shown bullying victimisation as another key covariate of repeated attempted suicide among SHS students in Ghana. Although this is the first study to provide this evidence from Ghana, the evidence in itself is not entirely surprising, as the CDC has suggested a strong association between bullying victimisation and high levels of suicide-related behaviours among young people. ${ }^{25}$ Whereas our finding is contrary to evidence among students in Association of Southeast Asian Nations which found bullying victimisation as being associated with suicidal ideation rather than suicidal attempts, it is consistent with previous evidence from Ghana that suicide attempt is significantly associated with bullying victimisation among SHS students. ${ }^{6}$

\section{Limitations}

The relative risk of depression, anxiety disorders including obsessive compulsive disorder, personality disorders and post-traumatic stress disorder are associated with the risk of suicide attempt ${ }^{26}$ which was not considered in the current analysis. This implies that other variables except marijuana use could be potential confounders of the association between marijuana use and repeated attempted suicide among SHS students in the Ghanaian context. Also, due to the nature of the GSHS which adopted a selfreported questionnaire and sometimes recall over a long time, recall bias is inevitable due to the subjective nature of the responses. However, in assessing marijuana use and suicidal attempts among SHS students, we strongly argue that the self-report method is highly considered which has been adopted by other researchers in Ghana, ${ }^{7}$ other sub-Saharan African countries ${ }^{14}$ and high-income contexts. $^{22} 27$

Moreover, due to the cross-sectional nature of the design of GSHS, this analysis did not allow for drawing causal inferences; however, the strength of the analysis lies in the adaptation of a matching procedure very much suited for such surveys in observational studies. ${ }^{18}$

\section{Implications}

Marijuana use among school-going adolescents is on the rise and has become a major public health concern in Ghana. The prevalence of marijuana use was found to be significantly associated with school grade, weekly smoking exposure, parental smoking, alcohol intake and truancy. Previous studies have found a strong link between 
Table 4 Correlates of marijuana use with repeated attempted suicide among senior high school students in Ghana, WHO GSHS, $2012^{15}$

\begin{tabular}{|c|c|c|c|}
\hline Covariate & Modified Poisson & Modified Logistic & Modified Probit \\
\hline & aPR (95\% Cl) & $\mathrm{aOR}(95 \% \mathrm{Cl})$ & $\mathrm{a} \beta(95 \% \mathrm{Cl})$ \\
\hline \multicolumn{4}{|c|}{ Marijuana use } \\
\hline No & Ref & Ref & Ref \\
\hline Yes & $3.02(1.67 \text { to } 5.43)^{\star \star \star}$ & $5.06(3.19 \text { to } 11.64)^{\star \star \star}$ & $0.95(0.49 \text { to } 1.41)^{\star \star \star}$ \\
\hline \multicolumn{4}{|l|}{ Sex } \\
\hline Female & Ref & Ref & Ref \\
\hline Male & 1.06 (0.55 to 2.07$)$ & 1.08 (0.47 to 2.45$)$ & $0.04(-0.37$ to 0.44$)$ \\
\hline \multicolumn{4}{|l|}{ Age group } \\
\hline$\leq 17$ & Ref & Ref & Ref \\
\hline $18+$ & 1.19 (0.56 to 2.51$)$ & 1.24 (0.50 to 3.10$)$ & $0.09(-0.36$ to 0.55$)$ \\
\hline \multicolumn{4}{|c|}{ Experience of hunger } \\
\hline No & Ref & Ref & Ref \\
\hline Yes & 1.31 (0.61 to 2.79$)$ & 1.38 (0.56 to 3.44$)$ & $0.14(-0.29$ to 0.57$)$ \\
\hline \multicolumn{4}{|c|}{ Bullying victimisation } \\
\hline No & Ref & Ref & Ref \\
\hline Yes & $3.10(1.63 \text { to } 5.89)^{\star \star \star}$ & $3.70(1.74 \text { to } 7.88)^{\star \star \star}$ & $0.69(0.29 \text { to } 1.09)^{\star \star \star}$ \\
\hline \multicolumn{4}{|c|}{ Social support at school } \\
\hline No & Ref & Ref & Ref \\
\hline Yes & 1.18 (0.56 to 2.49$)$ & 1.23 (0.48 to 3.17$)$ & $0.14(-0.35$ to 0.63$)$ \\
\hline \multicolumn{4}{|l|}{ Loneliness } \\
\hline No & Ref & Ref & Ref \\
\hline Yes & 2.02 (0.54 to 1.95) & 1.03 (0.46 to 2.28$)$ & $0.03(-0.37$ to 0.44$)$ \\
\hline \multicolumn{4}{|c|}{ Engaging in physical fights } \\
\hline No & Ref & Ref & Ref \\
\hline Yes & 1.31 (0.62 to 2.73 ) & 1.39 (0.56 to 3.44$)$ & $0.17(-0.30$ to 0.64$)$ \\
\hline
\end{tabular}

aPR denote adjusted prevalence ratio from Poisson regression; aOR denote adjusted OR from Logistic regression and a $\beta$ denote normalised coefficient estimate from Probit regression; Ref denotes Reference category used for inferences; $p$ value indication: ${ }^{\star} p<0.05,{ }^{* \star} p<0.01$, ${ }^{* * *} \mathrm{p}<0.001$.

GSHS, Global School-Based Student Health Survey.

marijuana use and suicidal attempts, both at the community level, among patients with psychiatric disorders and among school-going adolescents. ${ }^{627}$ Our current analysis shows that marijuana use does influence the onset of suicidal attempts and repeated attempted suicide among SHS students in Ghana. Early identification of the potential risk and protective factors is recommended to inform school-based interventions. Special attention is required for suicide attempters with a history of repeated attempts and current marijuana use among SHS students in Ghana. In particular, with the constant pressure on the government to legalise the recreational use of marijuana in Ghana, we recommend that policymakers consider the evidence of the risk among adolescents and other young people in the country. National level structured schoolbased substance abuse interventions and health promotion programmes would be useful. Incorporation of the harmful effects of substance abuse in the curricula and examinations would be key.
Author affiliations

${ }^{1}$ Department of Community Health, University of Ghana Medical School, College of Health Sciences, University of Ghana, Accra, Ghana

${ }^{2}$ Department of Psychiatry, Korle Bu Teaching Hospital, Accra, Greater Accra, Ghana ${ }^{3}$ National Cardiothoracic Centre, Korle Bu Teaching Hospital, Accra, Greater Accra, Ghana

${ }^{4}$ Department of Family and Community Health, School of Public Health, University of Health and Allied Sciences, Hohoe, Volta Region, Ghana

${ }^{5}$ Department of Psychology, School of Social Sciences, University of Ghana College of Humanities, Accra, Greater Accra, Ghana

Acknowledgements This study was based on public data from WHO and CDC. We are grateful to all respondents, interviewers and GSHS Ghana team who made the GSHS, 2012 in Ghana possible.

Contributors JT, GE-F and AEY developed the concept. JT analysed the data. JT, GE-F, SMS, NK, EN-BQ and AEY contributed to writing the first draft manuscript. All the authors reviewed the final version of the manuscript before submission.

Funding The authors have not declared a specific grant for this research from any funding agency in the public, commercial or not-for-profit sectors.

Competing interests None declared.

Patient consent for publication Not required. 
Ethics approval The Ghana SHS GSHS ethical approval was obtained from the Institutional Review Board at Middle Tennessee State University. The reference number for Ghana GSHS was GHA_2012_GSHS_v01.

Provenance and peer review Not commissioned; externally peer reviewed.

Data availability statement Data are available in a public, open access repository. Dataset downloaded from free online. https://extranet.who.int/ncdsmicrodata/index. php/catalog/422/get_microdata.

Open access This is an open access article distributed in accordance with the Creative Commons Attribution Non Commercial (CC BY-NC 4.0) license, which permits others to distribute, remix, adapt, build upon this work non-commercially, and license their derivative works on different terms, provided the original work is properly cited, appropriate credit is given, any changes made indicated, and the use is non-commercial. See: http://creativecommons.org/licenses/by-nc/4.0/.

ORCID iDs

John Tetteh http://orcid.org/0000-0002-1986-4103

George Ekem-Ferguson http://orcid.org/0000-0002-9293-6812

Swithin Mustapha Swaray http://orcid.org/0000-0002-6965-7110

Emmanuel Nii-Boye Quarshie http://orcid.org/0000-0002-8720-2355

\section{REFERENCES}

1 Olawole-Isaac A, Ogundipe O, Amoo EO, et al. Substance use among adolescents in sub-Saharan Africa: a systematic review and meta-analysis. S Afr J CH 2018;12:79-83. 83.

2 World Drug Report. Drugs and age drugs and associated issues among young people and older people. United nations publishers, 2018. Available: https://www.unodc.org/wdr2018 [Accessed $30 \mathrm{Apr}$ 2020].

3 Oppong Asante K, Kugbey N, Osafo J, et al. The prevalence and correlates of suicidal behaviours (ideation, plan and attempt) among adolescents in senior high schools in Ghana. SSM Popul Health 2017;3:427-34.

4 Maria-Goretti A. Parliament of Ghana passes historic new drug law paving the way for a West African approach, 2020. Available: https:// idpc.net/blog/2020/04/parliament-of-ghana-passes-historic-newdrug-law-paving-the-way-for-a-west-african-approach [Accessed 4 Jun 2020].

5 Johnston LD, Miech RA, O'Malley PM, et al. Monitoring the future national survey results on drug use: 1975-2017: overview, key findings on adolescent drug use. Ann Arbor: The University of Michigan, Institute for Social Research, 2018. http://www. monitoringthefuture.org/pubs/monographs/mtf-overview2017.pdf

6 Oppong Asante K. Cannabis and amphetamine use and its psychosocial correlates among school-going adolescents in Ghana. Child Adolesc Psychiatry Ment Health 2019;13:33.

7 Quarshie EN-B, Cheataa-Plange HV, Annor F, et al. Prevalence of suicidal behaviour among nursing and midwifery college students in Ghana. Nurs Open 2019;6:897-906.

8 WHO. The health and social effects of nonmedical cannabis use. Geneva, Switzerland: World Health Organization (WHO), 2016. https://search.ebscohost.com/login.aspx?direct=true\&scope=site\& $\mathrm{db}=$ nlebk\&db=nlabk\&AN=2260116

9 National Institute on Drug Abuse. Marijuana, 2019. Available: https:// www.drugabuse.gov/publications/drugfacts/marijuana [Accessed 15 May 2020].
10 Volkow ND, Baler RD, Compton WM, et al. Adverse health effects of marijuana use. N Engl J Med 2014;370:2219-27.

11 Paruk S, Burns JK. Cannabis and mental illness in adolescents: a review. South Afr Fam Pract 2016;58:S18-21.

12 World Health Organization. Preventing suicide: a global imperative. World Health Organization, 2014.

13 Quarshie EN-B, Waterman MG, House AO. Self-harm with suicidal and non-suicidal intent in young people in sub-Saharan Africa: a systematic review. BMC Psychiatry 2020;20:234.

14 Carvalho AF, Stubbs B, Vancampfort D, et al. Cannabis use and suicide attempts among 86,254 adolescents aged 12-15 years from 21 low- and middle-income countries. Eur Psychiatry 2019;56:8-13.

15 Baiden P, Kuuire VZ, Shrestha N, et al. Bullying victimization as a predictor of suicidal ideation and suicide attempt among senior high school students in Ghana: results from the 2012 Ghana global school-based health survey. J Sch Violence 2019;18:300-17.

16 Ghana-WHO. Global school-based student health Survey-Ghana senior high. Geneva, Switzerland: World Health Organization, 2015. https://extranet.who.int/ncdsmicrodata/index.php/catalog/422/ download/3179

17 von Elm E, Altman DG, Egger M, et al. The strengthening the reporting of observational studies in epidemiology (STROBE) statement: guidelines for reporting observational studies. Ann Intern Med 2007;147:573-7.

18 Rubin DB, Thomas N. Combining propensity score matching with additional adjustments for prognostic covariates. J Am Stat Assoc 2000;95:573-85.

19 Baum CF. Propensity score matching regression discontinuity limited dependent variables, 2013. Available: http://fmwww.bc.edu/ EC-C/S2013/823/EC823.S2013.nn12.slides.pdf [Accessed 13 Dec 2019].

20 Hormenu T, John Elvis HJ, Thomas S, et al. Psychosocial determinants of marijuana utilization among selected junior high school students in the central region of Ghana. JPMC 2018;2:43-57.

21 Oppong Asante K. Cannabis and amphetamine use and its psychosocial correlates among school-going adolescents in Ghana. Child Adolesc Psychiatry Ment Health 2019;13:33.

22 Peltzer K, Pengpid S. Suicidal ideation and associated factors among students aged 13-15 years in association of Southeast Asian nations (ASEAN) member states, 2007-2013. Int J Psychiatry Clin Pract 2017;21:201-8.

23 Jessor R. Problem behavior theory and adolescent health: the collected works of Richard Jessor. 2. Springer, 2017.

24 Delforterie MJ, Lynskey MT, Huizink AC, et al. The relationship between cannabis involvement and suicidal thoughts and behaviors. Drug Alcohol Depend 2015;150:98-104.

25 CDC. The relationship between bullying and suicide: what we know and what it means for school. National center for injury prevention and control: centre for disease control, 2014. Available: https://www. cdc.gov/violenceprevention/pdf/bullying-suicide-translation-final-a. pdf [Accessed 15 May 2020].

26 Witt K, Milner A, Spittal MJ, et al. Population attributable risk of factors associated with the repetition of self-harm behaviour in young people presenting to clinical services: a systematic review and metaanalysis. Eur Child Adolesc Psychiatry 2019;28:5-18.

27 Sellers CM, Diaz-Valdes Iriarte A, Wyman Battalen A, et al. Alcohol and marijuana use as daily predictors of suicide ideation and attempts among adolescents prior to psychiatric hospitalization. Psychiatry Res 2019;273:672-7.

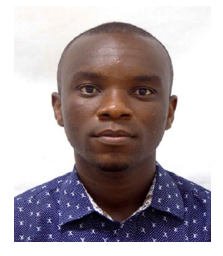

John Tetteh has obtained a bachelor's degree in Public Health from the School of Public Health, University of Health and Allied Sciences, Hohoe, Ghana, and the Higher National Diploma in Statistics from Accra Technical University. He currently is a senior research assistant at the Department of Community Health, University of Ghana Medical School and a young researcher who has served as a project file coordinator for several research projects and has several research publications. His main research interests include applying higher statistical models to any complex survey data to influence international and national health and social policy. 